\title{
NHS dentistry and our new government
}

\author{
Susie Sanderson, Chair, BDA Executive Board
}

If all goes to plan, by the time you read this the UK general election will be all over and we'll have had a couple of days to say, 'There we are then. I knew they'd get in'. As I write, the identity of the 'they' party is genuinely anyone's guess and today has seen the BBC News Channel dominated by, 'Row mounts over hung parliament' and, lowering itself rather disarmingly in a pastiche of the Daily Mail to entice us to read, 'How a loser can still win'.

Oddly, after hours of lobbying sitting MPs and prospective parliamentary candidates during the political party conferences and in the weeks leading up to the announcement of the election, I have a mildly curious view of the media rumpus. The BDA is an apolitical organisation and, while the major party leaders, whom one Radio 4 commentator described as 'a workhorse and two show ponies', dance around each other, this is a brief window to reflect on the last few years and what we have learned about the behaviour of governments.

The appalling introduction of the 2006 contract in England triggered the Commons Health Select Committee, in its report about Dental Services in 2008, to be hugely critical of, amongst other things, the way the contract was implemented, the lack of pre-testing and inconsistency in the standard of PCT commissioning. Four years on and the barbs within a cynical contract still lurch out to damage particularly the unwary and even the well informed. Calls to the BDA have escalated with 1,000 members contacting the BDA's NHS advice line every month - and they continue to demonstrate tragic distress. Throughout, we have insisted noisily that dentists need to be rewarded properly to have patients rather than targets at the forefront of their minds. And the public does not want its clinicians distracted by the (dis)incentives of targets either. Outcomes, quality and key performance indicators are the new targets though and I have little argument with these as long as they are the correct indicators genuinely to improve health and are properly funded to be achievable. Practice owners take all the risks and provide the infrastructure. Their responsibilities are not only to the safety and care of their patients but also to the wellbeing of people working in their businesses.

\section{'STRAIGHTFORWARD' AND 'COLLABORATION' WERE MISSING FROM THE 2006 CONTRACT}

There is no avoiding, however, the economic challenges for healthcare in the next few years. And there is no avoiding the steely (no pun intended) purpose of Sir David Nicholson,
Chief Executive of the NHS, to achieve £15 billion to £20 billion of productivity gains in the next four years. And, he says, the NHS will improve quality and reduce costs simultaneously. Hold those alarm bells for a moment.

The Steele suite of Enquiry, Report, Implementation Programme Board, Project Groups and Pilots has emerged from the Select Committee's recommendations for review of dental services. The pace of the pre-piloting stage has been worryingly fervent. The profession is involved across the work and we must insist that we are allowed to be proactive in describing our vision, not just reactive to Department of Health imperatives. Clearly, though, the Steele project is owned by the 20052010 government and if there is a change of administration, I am curious to see whether it is pursued. In any case, our demands for reform are accepted by all major parties, albeit oral health objectives are buried beneath calls to 'fight for a better NHS, (Brown), 'cut the deficit, not the NHS' (Cameron) and 'protect some [sic] front line services' (Clegg).

The stakeholders gain in the Steele work, assuming straightforward collaboration between the profession, civil service and government is an opportunity to be taken. But 'straightforward' and 'collaboration' were the depictions missing from the 2006 process and not entirely present in the much more recently introduced PDS Plus contract either. The 2006 changes placed NHS primary care dentistry firmly into the financial control of the primary care trusts with intended outcomes of improved access and quality. Private dentistry, providing care for significant parts of the population and through accreditation schemes, continues to raise the bar in quality and improvements in health. Whether that is universally true is arguable but irrelevant - all provider premises will anyway soon be subject to the same quality regulation through the Care Quality Commission.

But dentistry has a cost for its provision at the standard which patients should expect, regardless of who pays. Whichever colour the winning rosettes, the intentions of all the parties are the same: more quality, more productivity and more accountability for less cost. Ring those bells right now. In my practice expenses are rising daily and I am not prepared to compromise on quality. The leadership challenges for all of us are to sell our honest vision, straightforwardly collaborate, know what it costs to do the right things properly and not accept a situation where we can't.

DOI: $10.1038 /$ sj.bdj.2010.432 